Ya.S. Paranchuk, Y.V. Shabatura, O.O. Kuznyetsov

\title{
ELECTROMECHANICAL GUIDANCE SYSTEM BASED ON A FUZZY PROPORTIONAL-PLUS-DIFFERENTIAL POSITION CONTROLLER
}

\begin{abstract}
Purpose. The purpose is to develop solutions for the implementation of optimal laws of arms positioning, overshoot-free and requiring no post-adjustments. Method. The control model is based on the fuzzy set theory; and the structural modeling methodology is used to study the dynamics indices. Results. The structural scheme of the positional electromechanical system with a fuzzy proportional-plus-differential position controller and the method of control adaptation to the position reference signal change are obtained. Scientific novelty. A model of a fuzzy proportional-differential controller signal adaptation in the structure of a positional electromechanical system is proposed. Practical value. A solution is obtained for the implementation of optimal guidance process, non-overshooting and requiring no post-adjustments, also featuring the maximum weapons speed and minimal sensitivity to parametric disturbances. References 20, tables 1 , figures 12 .
\end{abstract}

Key words: fuzzy controller, positioning, adaptation, overshoot, speed.

Запропоновано позиційну електромеханічну систему наведення озброєння на основі адаптивного нечіткого пропориійнодиференційного (ПД) регулятора положення. Створено структурну Simulink-модель системи позиціонування озброєння основі нечіткої адаптивної моделі керування. Проведено комп'ютерні дослідження динаміки прочесів позиціонування при використанні пропориійного та запропонованого адаптивного нечіткого ПД регулятора положення. Результати досліджень показали, щзо при використанні нечіткої адаптивної моделі керування процесом позиціонування реалізуються оптимальні без перерегулювання та режимів дотягування закони руху озброєння. Бібл. 20, табл. 1, рис. 12.

Ключові слова: нечіткий регулятор, позиціонування, адаптація, перерегулювання, швидкодія.

Предложено позииионную электромеханическую систему наведения вооружения на основе адаптивного нечеткого пропориионально-дифференциального (ПД) регулятора положения. Разработано структурную Simulink-модель системь наведения вооружения на основе нечеткой адаптивной модели управления. Проведены компьютерные исследования динамики процессов позиционирования при использовании пропориионального и предложенного адаптивного нечеткого ПД регулятора положения. Результаты исследований показали, что при использовании нечеткой адаптивной модели управления процессом позиционирования реализуются оптимальные без перерегулирования и режимов дотягивания законы движения вооружения. Библ. 20, табл. 1, рис. 12.

Ключевые слова: нечеткий регулятор, позиционирование, адаптация, перерегулирование, быстродействие.

Introduction. At the present stage of development of armaments of missile troops and artillery, there is a tendency to increase the range, increase mobility and accuracy of weapons. This trend is realized both in the creation of new high-precision means of destruction, and in the process of modernization of existing ones.

Samples of these weapons, which were created and manufactured in the 70-80s of last century, do not fully meet modern requirements for accuracy and speed of guidance. The reason for this is the imperfect element base, system and circuitry of control systems of the specified time period, which today is mostly morally obsolete and physically worn out.

In view of this, it can be argued about the relevance and feasibility of directing efforts and finances to the modernization of these models of missile technology in the direction of improving their tactical and technical characteristics $[1,2]$.

Problem definition. Mentioned models of missile weapons include, for example, rocket-propelled grenade launchers based on the BM-21 combat vehicle, or others. The process of guiding the package of guides (PGs) in azimuth and pitch in these machines is implemented by manual drive or non-positional electromechanical system (EMS) according to the scheme «electromechanical amplifier - DC motor» using the appropriate forming and stabilizing feedbacks [2].

This EMS contains backlash, elasticity, in particular a pair of torsions, gaps and other nonlinearities. It is characterized by the inconsistency of the moment of inertia and load at different loads of PGs by missiles, as well as asymmetry of the load at different directions of movement. These factors negatively affect the dynamics and statics of the process of positioning PGs in the guidance process.

Control of the movement of the guide package (the process of guidance, positioning) in both planes in the existing EMS is performed manually from the remote control. There is no position adjustment circuit. In such a control system, the efficiency and accuracy of weapons guidance is significantly influenced by a subjective factor - the qualification of the operator (gunner). To eliminate this factor, it is advisable to automate the process of positioning the PGs by using a high-precision sensor and the setter of the aiming angle and the implementation of automatic angle adjustment by the mismatch signal. This approach eliminates the influence of the subjective factor and guarantees the predicted indicators of the dynamics and statics of the process of weapons guidance, in particular the static positioning accuracy.

Analysis of recent research and publications. It is known that positional electric drives are able to implement the desired laws and trajectories of the actuators as well as the quality of static accuracy and speed of positioning. Therefore, the task of obtaining the highest control speed in the absence of overregulation and traction modes at «creeping» speeds and the required static positioning accuracy can be considered relevant and important in the modernization and optimization of (C) Ya.S. Paranchuk, Y.V. Shabatura, O.O. Kuznyetsov 
electromechanical guidance systems in azimuth and pitch of the BM-21 combat vehicle [3, 4].

An effective system approach to solve this problem is the implementation of an electromechanical control system of the PG movement according to the scheme «pulse-width converter - DC motor» (PWC-DCM) according to the subordinate control principle using internal control circuits of current (torque) and speed of the motor and their standard setting for the modular optimum and additionally introduced external position control circuit $[5,6]$.

The classic approach in the construction of positional automatic control systems (ACS) is the use of proportional (P) position controller (PC) [3-7]. This structure of the ACS makes it possible to obtain the desired indicators of the dynamics of positioning in the modes of large displacements in the implementation of the trapezoidal tachogram of the electric drive movement.

But when working out tasks for smaller movements, which are performed at lower speeds, the positioning processes are accompanied by traction modes, the duration of which is commensurate with the braking time when working out large movements [8]. To eliminate these modes, a parabolic PC is used, which is most often included in the control circuit of the three-circuit control system with internal control circuits of current and speed with proportional-integral $(\mathrm{PI})$ and $\mathrm{P}$ regulators, respectively, and their standard settings [8].

The predicted dynamics of the positioning process in the above structures is achieved under the condition of constant load torque, initial position, moment of inertia and other parameters. If these conditions are not met, the dynamics of the actuator movement will deviate from the optimal, which corresponds to the selected structure of the ACS and the principle of adjusting the coordinate controllers.

To eliminate the negative impact on the optimal laws of motion of the above coordinate and parametric perturbations in modern control models and with incomplete information about the state of the control object, intelligent approaches based, in particular, on fuzzy logic algorithms are used [9-13]. Such control models are used in positional ACS, including for tasks of optimization and adaptation of control in the modes of positioning and tracking in the conditions of action of coordinate and parametric perturbations.

It is known that classical proportional-differential (PD) regulators are well distinguished by their properties of improving the quality of transients, in particular in positioning systems in positioning and tracking modes. In [13-15] it is shown that fuzzy PD regulators and fuzzy proportional-integral-differential (PID) regulators provide a significant improvement in the quality of system dynamics, in particular positional, compared to the use of classical PID regulators and especially in cases where in the control object there are various kinds of nonlinearities and parametric uncertainties.

The main advantage and feature of fuzzy control is the possibility of its effective use in systems with complex mathematical descriptions and parametric and coordinate fluctuations, existing uncertainties, elasticities, nonlinearities, backlashes, gaps, etc.
In addition, as shown in [14-18], the advantages of fuzzy controllers are their simplicity, as well as low sensitivity to parametric changes and uncertainties in the control object due to the mechanism of rapid information processing based on fuzzy inference models. These features are inherent in the mechanism of weapons guidance of the BM-21. This further argues for the feasibility of using fuzzy control models to improve the dynamics and statics of the processes of positioning PGs.

The goal of the paper is to develop the structure and study the effectiveness of using an adaptive fuzzy PD position regulator to improve the accuracy and efficiency of weapons guidance by implementing the optimal laws of PG movement on the full range of position control in the structure of positional three-circuit EMS for guidance of the PGs of the combat vehicle during its modernization.

Therefore, the task of developing system solutions to implement the exact positioning of the PGs of the BM-21 without over-regulation and modes of tightening under the conditions of these perturbations and parametric changes for the system of vertical guidance of the PGs is relevant and important.

At the present stage of EMS development there is a tendency of wide application for the problems of automatic coordinate control and optimal control of modes of methods of the theory of artificial intelligence, the components of which is a transformation of typical proportional-integral, proportional-differential and proportional-integral-differential control laws on their fuzzy or neurofuzzy versions [13-20].

The object of control of the considered EMS is the mechanism of vertical guidance of the PGs which belongs to the class of complex systems, because it contains nonlinear elements, uncertainties, mechanical links with backlash, delay, limited stiffness, the parameters of which are also not constant and change in the process of guidance and depend on the level of missile loading of the PGs and other factors. In view of this, we use a fuzzy version of the proportional-differential PC for the position control circuit of the EMS under consideration, which a priori gives the position control circuit adaptive properties that are invariant to the action of parametric perturbations. In other words, the use of fuzzy PD position regulator should ensure the implementation of the desired optimal without overregulation and modes of traction at maximum speed of the laws of motion of the PGs in the full range of position regulation in the space of real parametric changes and coordinate perturbations.

For this purpose, we use the general structure of the fuzzy controller (FC), on the basis of which we can get different versions of fuzzy proportional-differential regulators of direct action. As the input signals of FC we take the error of adjusting the aiming angle $e(t)=\varphi_{\text {ref }}(t)-\varphi(t)$ and its derivative $d e(t) / d t \cong\left(e\left(t_{i}\right)-e\left(t_{i-1}\right)\right) /\left(t_{i}-t_{i-1}\right)-$ the rate of error change. Given the fact that currently these regulators in the structures of the ACS are implemented on a digital element base (microcontrollers), its mathematical model is presented in discrete form. In this approach, the error signal derivative at the input of the FC is fed in finite increments. 
The mathematical model of the classical analog PD regulator is presented by the following equation:

$$
u(t)=k_{r}\left[e(t)+T_{d} \cdot d e(t) / d t\right],
$$

where $e(t), u(t)$ are the input and output signals, $k_{r}, T_{d}$ are the transmission ratio and differentiation constant of the PD regulator, respectively.

The transition in (1) to discrete time makes it possible to obtain a mathematical model of the PD controller for its digital implementation:

$$
u(k)=k_{r}\left[\frac{T_{d}}{T_{0}} \cdot \Delta e(k)+e(k)\right],
$$

where $T_{0}$ is the time quantization interval; $k=1,2,3, \ldots$ is the discretization step number in time; $\Delta e(k)=e(k)-e(k-1)$.

The main requirement for positional EMS of the guidance of the PGs for a given angle $\varphi_{\text {ref }}$ is the implementation of optimal laws of motion of guides in the positioning process (without overregulation and tightening modes) at maximum speed on the full range of position regulation under real coordinate and parametric perturbations.

The values of the maximum speed, acceleration and voltage of the PWC in the proposed positional EMS of the guidance of the PGs are taken the same as in the real existing system of providing movement of the PGs of the BM-21 combat vehicle.

The structure of positional EMS. The block diagram of the proposed three-circuit positional EMS for guidance of the PGs of the BM-21 combat vehicle with adaptive fuzzy PD position regulator is shown in Fig. 1. The electric drive of such EMS is realized according to the reversible scheme of PWC-DCM. The regulator of the internal circuit of the current is proportional-integral, and of the speed circuit is proportional.

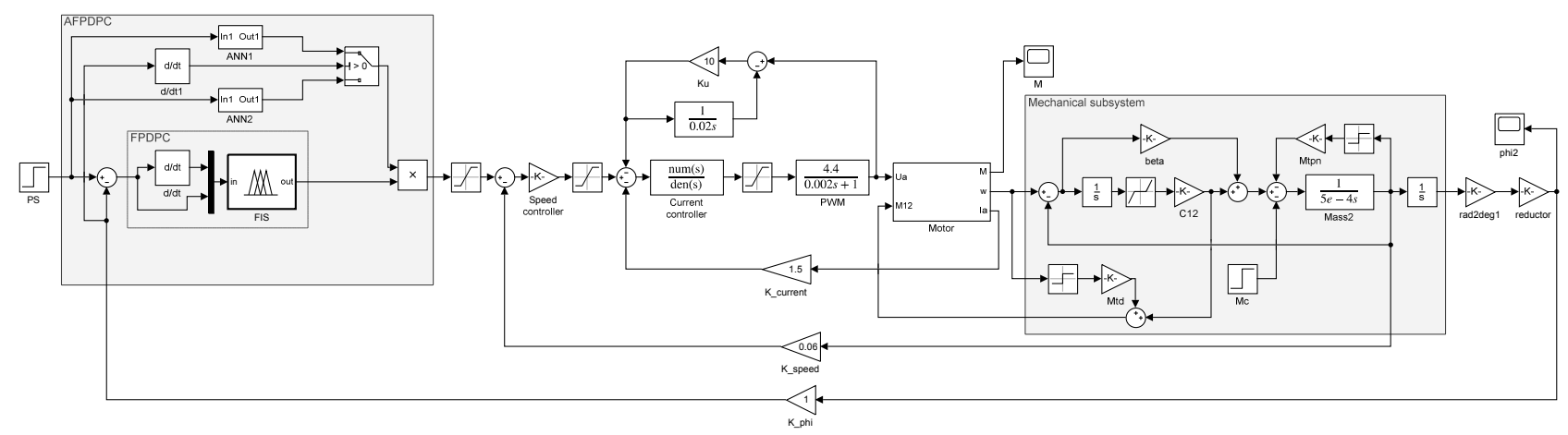

Fig. 1. Block diagram of the EMS of the vertical guidance of the PGs with fuzzy PD position regulator

To study the dynamics and statics of the guidance process of the PGs of the proposed positional EMS, its structural model is created in the Matlab Simulink application with the option to use to compare the dynamics of the classical proportional and the proposed adaptive fuzzy proportional-differential controller in the position control circuit.

Testing of the built three-circuit position with the above-mentioned subordinate adjustment of the EMS coordinates of the guidance of the PGs is performed when using in the control circuit of the position of the classical proportional controller to adjust it to the modular optimum.

Figure 2 shows the time dependencies of the aiming angle adjustment obtained for this model for three positioning angles: $17^{\circ}, 35^{\circ}$ and $60^{\circ}$. The P-position controller is set to the optimal dynamics (optimal law of motion) for the positioning angle $\varphi_{\text {ref }}=35^{\circ}$ with transmission factor $k_{p n}=2.11$. When positioning at other guidance angles, overregulation and tightening modes are observed.

Synthesis of fuzzy PD. The synthesis of the fuzzy PD regulator and the strategy of fuzzy control of the position of the PGs are based on the use of empirically acquired knowledge about the design, control features, perturbations and indicators of the positioning modes of the PGs of the BM-21.

The fuzzy inference system (FIS) (see Fig. 1) of the PD position controller is presented by the Mamdani model which has two inputs: for proportional $x_{1}=e(t)$ and

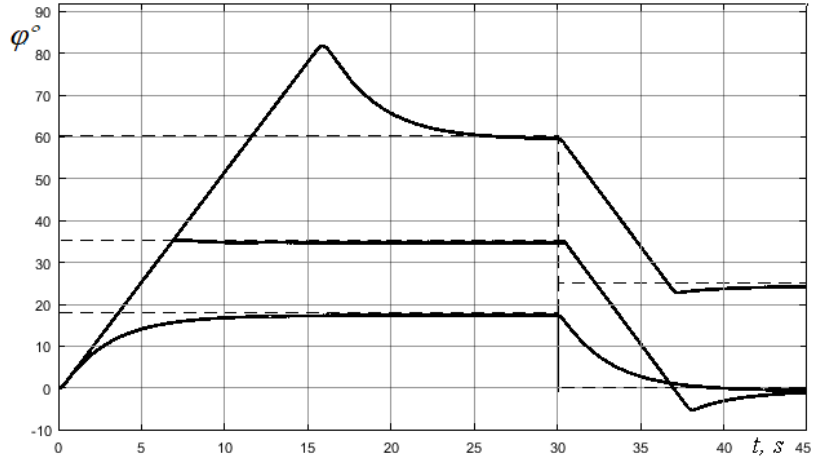

Fig. 2. Reactions $\varphi(t)$ of the EMS to abrupt control signals with proportional $\mathrm{PC}$ at the initial setting of the $\mathrm{PGs}$ at angles of $17^{\circ}, 35^{\circ}$ and $60^{\circ}$ and the subsequent one at $0^{\circ}, 0^{\circ}$ and $35^{\circ}$, respectively

differential $x_{2}=d e(t) / d t$, where $e(t)$ is the error of angle adjustment $e(t)=\varphi_{\text {ref }}(t)-\varphi(t)$ (where $\varphi_{\text {ref }}(t), \varphi(t)$ are the signals of the set and current positioning angle of the PGs, respectively).

For the linguistic description of the input variables $x_{1}$ and $x_{2}$, two trapezoidal external $(N, P)$ and one triangular internal term $(Z)$ with symmetric ranges of change are accepted (Fig. 3).

For the linguistic description of the original linguistic variable of the FIS $U_{F I S}$ which gives the control signal of the speed controller $U_{c . \omega}=U_{F I S}$, two trapezoidal external $(\mathrm{Nu}, \mathrm{Pu})$ and one triangular internal term $(\mathrm{Zu})$ with symmetric ranges of change are accepted (Fig. 4). 
The functional relationship between the angle reference signal $\varphi_{\text {ref }}$ and the output signal of the FIS $U_{F I S}$, which is the reference signal $U_{c . \omega}$ of the P-speed controller in such a control strategy is given in linguistic form, namely a set of fuzzy rules of the type (IF...AND...THEN).

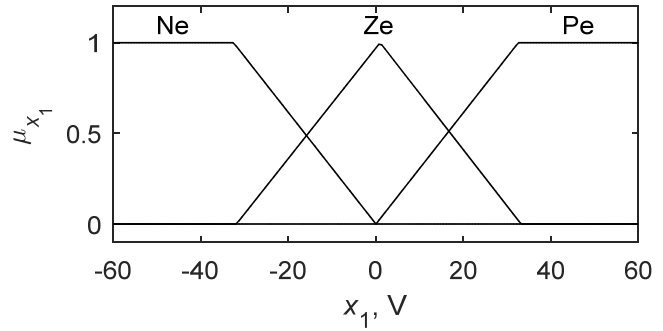

Fig. 3. FIS membership functions of input variables $x_{1}$ and $x_{2}$

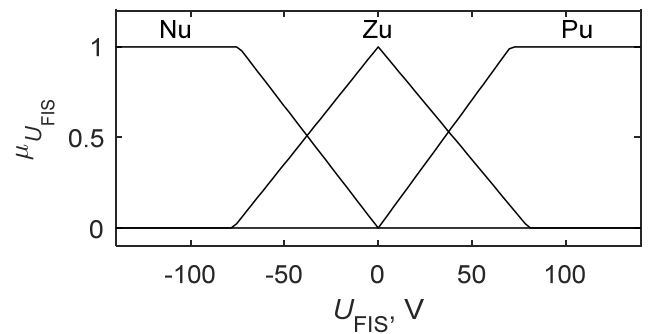

Fig. 4. FIS source variable membership functions $U_{F I S}$

The FIS rule base is formed on the basis of the analysis of the change of the control error of the position $e(t)=\varphi_{\text {ref }}(t)-\varphi(t)$, its derivative $d e(t) / d t$ and the current angle of the position of the PGs $\varphi(t)$. The rule base was formed on the basis of comparison of time dependencies of change of desirable and actual (at proportional PC) reactions of EMS at positioning of the PGs on the angle $\varphi_{\text {ref }}=35^{\circ}$. The desired response corresponded to the optimal law of motion - positioning at maximum speed and stop without over-adjustment and traction mode. The optimal transmission factor of the P-position controller was calculated under the modular optimum condition.

The compiled rule base and other parametric and algorithmic degrees of freedom of the fuzzy PD regulator were specified by the results of mathematical experiments on the compiled Simulink model of the developed positional ACS (Fig. 1) by the value of the variant of the integrated quality indicator ( $T$ is the regulation time)

$$
I=\int_{0}^{\grave{O}} t \cdot e(t)^{2} d t \rightarrow \text { min. }
$$

The obtained rule base of fuzzy PD-position regulator is shown in Table 1.

Table 1

FIS rule base

\begin{tabular}{|l|c|c|c|c|}
\hline \multicolumn{2}{|c|}{} & \multicolumn{3}{|c|}{ Adjustment error $-x_{1}$} \\
\cline { 3 - 5 } \multicolumn{2}{|c|}{} & $N e$ & $Z e$ & $P e$ \\
\hline \multirow{2}{*}{$\begin{array}{l}\text { Derivative of } \\
\text { adjustment error - } \\
x_{2}\end{array}$} & $N d e$ & $N$ & $Z$ & $Z$ \\
\cline { 2 - 5 } & $Z d e$ & $N$ & $Z$ & $P$ \\
\cline { 2 - 5 } & $P d e$ & $Z$ & $Z$ & $P$ \\
\hline
\end{tabular}

Figure 5 shows the 3D surface of the output signal of the designed fuzzy PD-position controller on the plane of change of the input linguistic variables $x_{1}$ and $x_{2}$ of the designed FIS.

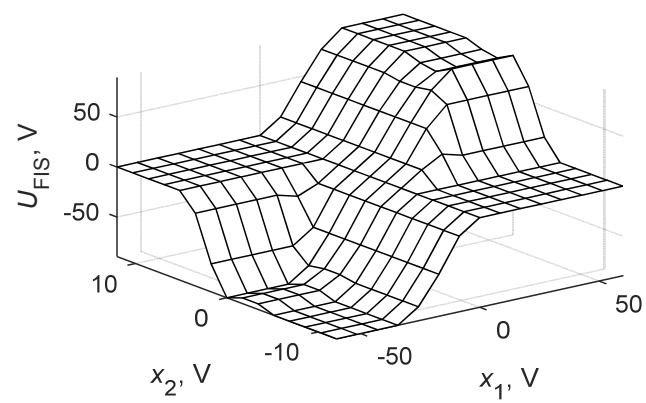

Fig. 5. Characteristics input/output $U_{F I S}\left(x_{1}, x_{2}\right)$ of the designed fuzzy PD-position controller

Study of positional EMS. The obtained reactions of EMS with the designed fuzzy PD-position regulator when testing control signals for small $\left(\varphi_{\text {ref }}=15^{\circ}\right.$ and $\left.0^{\circ}\right)$, medium $\left(\varphi_{\text {ref }}=35^{\circ}\right.$ and $\left.0^{\circ}\right)$ and large $\left(\varphi_{\text {ref }}=60^{\circ}\right.$ and $\left.0^{\circ}\right)$ displacement of the PGs are shown in Fig. 6.

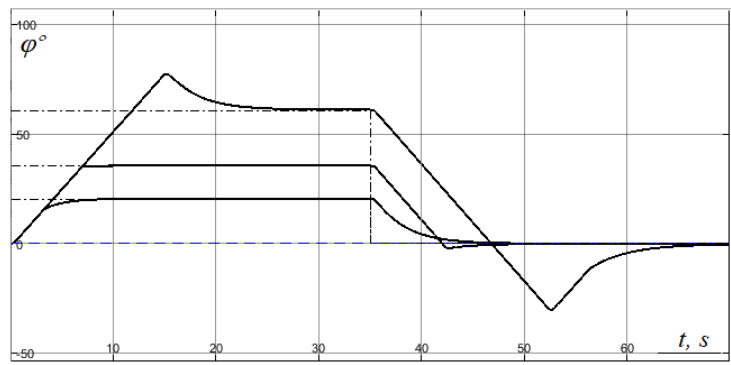

Fig. 6. EMS reactions with fuzzy PD-position regulator

In comparison with the P-regulator (see Fig. 2), when using a fuzzy $P D$ regulator, the position of overregulation and regulation time are smaller.

But to achieve complete invariance of indicators of dynamics and statics of positioning to the value of the control signal (to the value of displacement), i.e. to obtain optimal laws of motion of the PGs for any positioning angles only by changing the parametric and algorithmic degrees of freedom of the designed Mamdani FIS (fuzzy PD position regulator) - no succeeded.

Therefore, in order to obtain optimal laws of motion when positioning the PGs at any angles without overregulation and traction modes at the maximum possible speed, it is proposed to use the adaptation of the fuzzy PD-position regulator model to change the control signal $\varphi_{\text {ref }}(t)$. It is proposed to perform the adaptation by normalizing the output signal of the fuzzy PD controller:

$$
U_{F I S}^{n}=k_{n}\left(\varphi_{r e f}\right) \cdot U_{F I S}=U_{c . \omega},
$$

where $U_{F I S}^{n}$ is the normalized output signal of the fuzzy PD-position controller, which is the control signal of the speed controller $U_{c . \omega}$ of the positional EMS providing the movement of the PGs; $k_{n}\left(\varphi_{r e f}\right)$ is the dependence of the normalizing coefficient.

A series of mathematical experiments were performed on the Simulink model to obtain the normalizing functional dependence $k_{n}\left(\varphi_{\text {ref }}\right)$. For different admissible signals of the task $\varphi_{\text {ref }}$, the position of the PGs, the value of the normalizing coefficient $k_{n}$, at which the 
optimal law of motion of the PGs was obtained, is determined.

The analysis of the research results showed that this dependence is asymmetric with respect to the average positioning angle of $35^{\circ}$ and different in the modes of raising and lowering the PGs (for $\varphi_{\text {ref }}=35^{\circ} k_{n}=1$ ). This is explained by the active nature of the load torque, the reactive moment of friction, the different action of torsions, and so on. These factors in different ways affect the dynamics indicators of the movement when raising and lowering the PGs. The obtained dependencies $k_{n}\left(\varphi_{\text {ref }}\right)$ when raising $(\multimap)$ and lowering $(-)$ of the PGs are shown in Fig. 7.

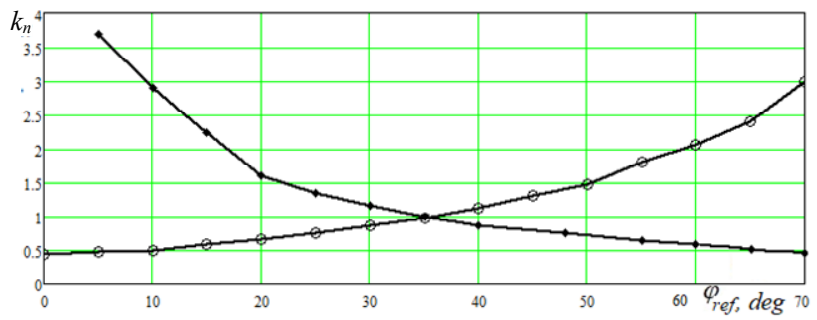

Fig. 7. Dependencies of the normalizing factor $k_{n}\left(\varphi_{r e f}\right)$ of the FIS output signal for the movement of the PGs up (๑) and down ()

These dependencies are reproduced in the structure of such an adaptive fuzzy PD-position controller (AFPDPC) by two artificial neural networks (ANN1 and ANN2, Fig. 8 and Fig. 1) of direct signal propagation or other static nonlinear functional transducers.

Figure 8 shows a block diagram of the proposed AFPDPC of the guide package, which indicates: PS position setter, FPPDS - fuzzy proportional-differential position controller, Plant - control object.

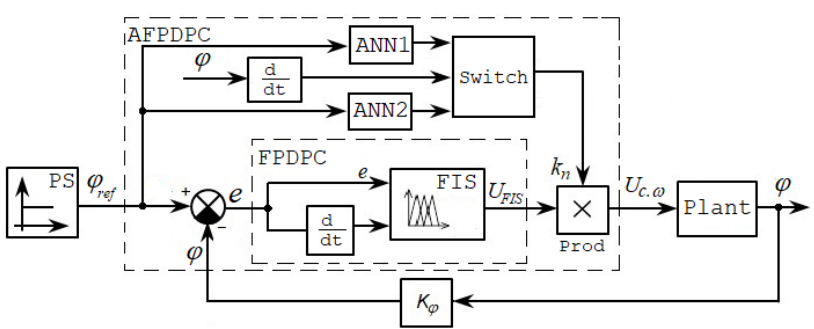

Fig. 8. Block diagram of adaptive fuzzy

PD-position regulator of EMS of guidance of the PGs

Switching between the branches up/down of the adaptation coefficient $k_{n}\left(\varphi_{r e f}\right)$. in the structure of AFPDPC is performed as a function of changing the speed (acceleration sign), which is implemented in the Switch (Fig. 8). At the output of the Switch, the current value of the normalizing factor $k_{n}$ is formed which is fed to the input of the multiplication element Prod at the output of which the speed reference signal $U_{c . \omega}$ is formed according to (4).

The obtained structural model of AFPDPC is implemented in the structure of the Simulink model of positional EMS of guidance of the PGs (see Fig. 1).

Figures 9, 10 show the time dependencies of the aiming angle $\varphi_{\text {ref }}(t)$ obtained on this model during the operation of two programs of changing in the discrete control signal $\varphi_{\text {ref }}(t)$ of the position of the PGs (.-.-.) during the operation of the proposed AFPDPC (-) and, for comparison, of the proportional PC (- - ) .

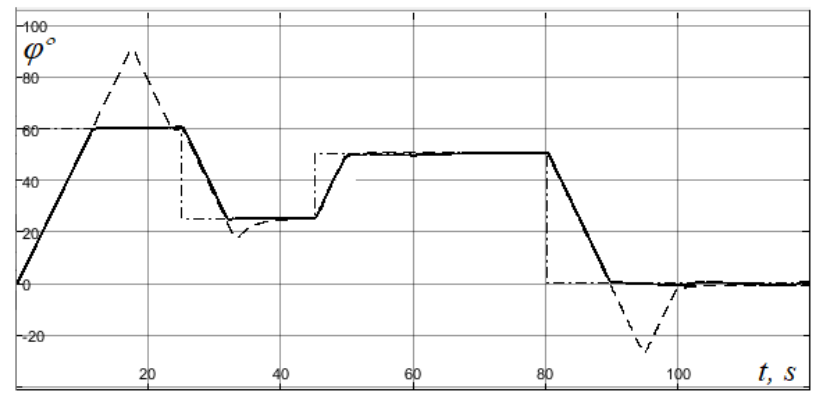

Fig. 9. Time dependencies $\varphi(t)$ at the PGs positioning at angles of $60^{\circ}, 25^{\circ}, 50^{\circ}$, and $0^{\circ}$ at proportional PC (---) and AFPDPC (—), (-.-.) - position reference signal

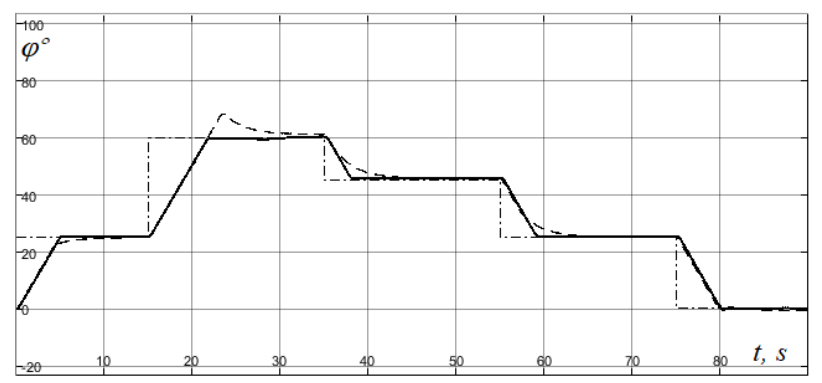

Fig. 10. Time dependencies $\varphi(t)$ at the PGs positioning at angles of $25^{\circ}, 60^{\circ}, 45^{\circ}, 25^{\circ}$, and $0^{\circ}$ at proportional PC (----) and AFPDPC (-), (-...) - position reference signal

According to the first program, PG was alternately set at angles $\varphi_{\text {ref }}=60^{\circ}, 25^{\circ}, 50^{\circ}$, and $0^{\circ}$ (Fig. 10), and according to the second one $\varphi_{\text {ref }}=25^{\circ}, 60^{\circ}, 45^{\circ}, 25^{\circ}$, and $0^{\circ}$ (Fig. 10). These time dependencies $\varphi(t)$ of the PG positioning process are obtained when they are loaded by missiles by $50 \%$.

The value of the accepted quality indicator (3) in the operation of the P-position regulator was 4.15 degrees $^{2} \cdot \mathrm{s}$, and in AFPDPC was 3.72 degrees $^{2} \cdot \mathrm{s}$ (Fig. 9, the first program) and 3.91 degrees $^{2} \cdot \mathrm{s}$ and 3.69 degrees $^{2} \cdot \mathrm{s}$, respectively, for the second program (Fig. 10). The improvement in quality when using AFPDPC was $10.4 \%$ and $5.6 \%$ for the first and the second program of change in $\varphi_{\text {ref }}(t)$, respectively.

A comparative analysis of the obtained time dependencies $\varphi(t)$ for the discrete (single) nature of the change $\varphi_{\text {ref }}(t)$ shows an improvement in the quality of dynamics during the operation of the proposed AFPDPC when positioning $\mathrm{PG}$ at different guidance angles regardless of the direction of movement (raising or lowering) in comparison with use of the classical P-regulator in a contour of position of EMS of guidance of the PG.

To obtain a more complete assessment of the dynamics of the synthesized positional EMS of the PG motion with AFPDPC, the guidance processes $\varphi(t)$ with sinusoidal change of the position reference signal $\varphi_{\text {ref }}(t)$ were studied (this mode of operation is not typical for the PG guidance mechanism). The obtained dependencies $\varphi(t)$ are shown in Fig. 11. 


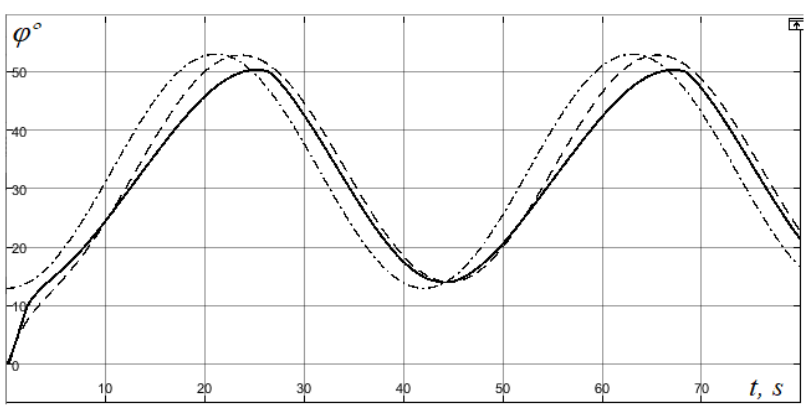

Fig. 11. Time dependencies $\varphi(t)$ of working off of a sinusoidal reference signal $\varphi_{\text {ref }}(t)(.---$.$) at proportional PC (----)$ and AFPDPC (-)

The main perturbations that affect the dynamics of the movement of the PGs in the proposed positional EMS of guidance are the moment of static load and the moment of inertia of the guidance mechanism of the PGs which change when they are loaded differently by missiles.

Figure 12 shows the processes $\varphi(t)$ obtained in the model when positioning the $\mathrm{PG}$ at an angle of $35^{\circ}$ followed by installation in the initial position of $0^{\circ}$ at $50 \%$ load (Fig. 12,a) and at full load (Fig. 12,b) during the operation of proportional PC and the proposed AFPDPC which illustrate the parametric sensitivity of the EMS of guidance of the PGs with these PC.

Analysis of the obtained positioning processes $\varphi(t)$ shows a lower sensitivity of the EMS with AFPDPC compared to the classical proportional PC.
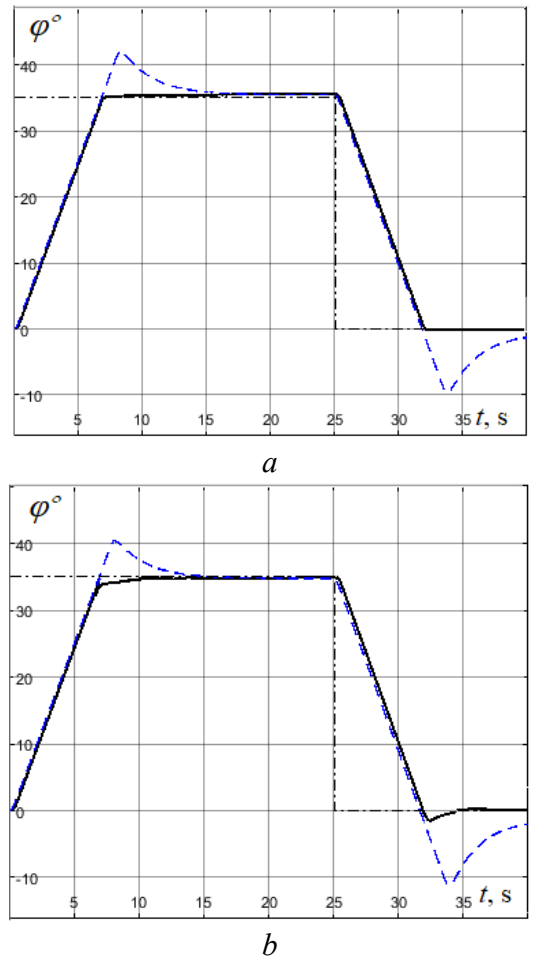

Fig. 12. Time dependencies $\varphi(t)$ at positioning of PG on an angle of $35^{\circ}$ and $0^{\circ}$ at proportional PC (----) and AFPDPC

$(-)$ for $50 \%(a)$ and $100 \%(b)$ of loading of $\mathrm{PG}$, (-... ) - position reference signal

\section{Conclusions.}

1. The expediency of using fuzzy control models to improve the indicators of dynamics and statics of the process of guidance of the PGs is substantiated.
2. The structure is developed and the fuzzy proportional-differential $\mathrm{PC}$ is designed with adaptation to the position reference signal.

3 . The structural model of the developed positional EMS of guidance of the BM-21 weapon is created and its realization in the Simulink application of Matlab code is executed.

4. Computer researches of indicators of dynamics of movement of PGs at installation of the weapon on various angles of guidance, various character of $\varphi_{\text {ref }}(t)$ and at various loadings of a package of guides are carried out.

5 . The obtained results of computer researches have shown that when using the designed adaptive fuzzy PD- position regulator, optimal without over-regulation and tightening modes and with maximum speed laws of movement of guide packets in the full range of guidance angles and at different loads of the PGs are realized.

6. When using the developed system solutions for the control circuit of the EMS adjustment position of the BM-21 armament guidance, a high level of robustness of the dynamics indicators is achieved until the change in the moment of static load and the moment of inertia of the guidance mechanism of the guide package.

Conflict of interest. The authors declare that they have no conflicts of interest.

\section{REFERENCES}

1. Krainyk L.V., Hrubel M.H., Yalnytskyi O.D. Analysis of development of the modern fighting wheeled machines. Systems of Arms and Military Equipment, 2017, no. 1 (49), pp. 126-131. Available at: http://www.hups.mil.gov.ua/periodicapp/article/17585/eng (accessed 12 October 2020). (Ukr).

2. BM-21 Combat Vehicle. Technical description and operating instructions. Moscow, Voenizdat Publ., 1982. 99 p. (Rus).

3. Kuznetsov B.I., Nikitina T.B., Kolomiets V.V., Bovdui I.V. Improving of electromechanical servo systems accuracy. Electrical Engineering \& Electromechanics, 2018, no. 6, pp. 3337. doi: https://doi.org/10.20998/2074-272X.2018.6.04.

4. Kuznetsov B.I., Nikitina T.B., Bovdui I.V., Kobilyanskiy B.B. Improving of electromechanical stabilization systems accuracy. Electrical Engineering \& Electromechanics, 2019, no. 2 , pp. 21-27. doi: https://doi.org/10.20998/2074272X.2019.2.04.

5. Paranchuk Ya.S., Chumakevych V.O., Evdokimov P.M., Moskalyk V.O. High-speed electromechanical guidance and stabilization system based on pulse-width converter with fuzzy control. Proceedings of International Scientific and Technical Conference "Problems of Enhancing the Energy Efficiency of the Electromechanical Converters in Electrical Energy Systems», Sevastopol, Ukraine, 2013, pp. 71-72. (Ukr).

6. Paranchuk Y., Evdokimov P., Kuznyetsov O. Electromechanical positioning system with a neuro-fuzzy corrector. Przeglad Elektrotechniczny, 2020, no. 9, pp. 52-55. doi: https://doi.org/10.15199/48.2020.09.11.

7. Chilikin M.G., Klyuchev V.I., Sandler A.S. Theory of Automated Electric Drives. Moscow, Energiya Publ., 1979. 616 p. (Rus).

8. Lebedev Ye.D., Neimark V.Ye., Pistrak M.Ya., Slezhanovskiy O.V. Control of DC Electric Drives with Semiconductor Converters. Moscow, Energiya Publ., 1970. 200 p. (Rus).

9. De Azevedo H. R., Branodao S. F. M., Da Mota Alves J. B. A fuzzy logic controller for DC motor position control. Proceedings of IEEE 2nd International Workshop on Emerging 
Technologies and Factory Automation (ETFA '93), 1993, pp. 18-27. doi: https://doi.org/10.1109/etfa.1993.396433.

10. Manikandan R., Arulmozhiyal R. Position control of DC servo drive using fuzzy logic controller. 2014 International Conference on Advances in Electrical Engineering (ICAEE), 2014, pp. 1-5. doi: https://doi.org/10.1109/icaee.2014.6838474.

11. Priymak B.I., Bondarenko M.M., Khalimovsky O.M. Fuzzy control of electromechanical objects. Bulletin of Scientific Works of Dniprodzerzhynsk State Technical University. Special Issue "Problems of Automated Electric Drive», 2007, pp. 308-311. (Ukr).

12. Lukichev D.V., Demidova G.L. Fuzzy control system of positioning servo drives of elastic coupling rotary supports, Vestnik IGEU, 2013, no. 6, pp. 60-64. Available at: http://vestnik.ispu.ru/sites/vestnik.ispu.ru/files/publications/str.6 0-64 0.pdf (accessed 12 October 2020). (Rus).

13. Paranchuk Y., Matsyhin A. The system of arc lengths regulation of an electric arc furnace with a neuro-controller, Przeglad Elektrotechniczny, 2013, vol. 89, no. 3A, pp. 271-273. Available at: http://pe.org.pl/articles/2013/3a/58.pdf (accessed 12 October 2020).

14. Ying H. Fuzzy Control and Modeling: Analytical Foundations and Applications, IEEE press, 2000. 342 p. Available at: https://ieexplore.iee.org/book/5263877 (accessed 12 October 2020).

15. Lozynskyy O., Paranchuk Y., Paranchuk R. Fuzzy control law of electrode travel in arc steelmaking furnace. 2015 16th International Conference on Computational Problems of Electrical Engineering (CPEE), 2015, pp. 103-106. doi: https://doi.org/10.1109/cpee.2015.7333349.

16. Mendel J. M., John R. I. B. Type-2 fuzzy sets made simple. IEEE Transactions on Fuzzy Systems, 2002, vol. 10, no. 2, pp. 117-127. doi: https://doi.org/10.1109/91.995115.

17. Paranchuk Ya.S., Paranchuk R.Ya. Neural Network System for Continuous Voltage Monitoring in Electric Arc Furnace. Naukovyi
Visnyk Natsionalnoho Hirnychoho Universytetu, 2016, iss. 2, pp. 74-80. Available at: http://nvngu.in.ua/index.php/en/archive/ondivisions-of-science/electrical-engineering/3398-neutral-networksystem-for-continuous-voltage-monitoring-in-electric-arc-furnace (accessed 12 October 2020).

18. Paranchuk Y.S., Paranchuk R.Y. Research of arc furnace electrical mode with a fuzzy control model. Electrical Engineering \& Electromechanics, 2020, no. 4, pp. 30-36. doi: https://doi.org/10.20998/2074-272X.2020.4.05.

19. Begian M.B., Melek W.W., Mendel J.M. Stability analysis of type-2 fuzzy systems. 2008 IEEE International Conference on Fuzzy Systems (IEEE World Congress on Computational Intelligence), 2008, pp. 947-953. doi: https://doi.org/10.1109/fuzzy.2008.4630483.

20. Lozynskyy O., Paranchuk Y., Kobylianskyi O. Simulink model of electric modes in electric arc furnace. 2017 IEEE International Young Scientists Forum on Applied Physics and Engineering (YSF), 2017, pp. 54-57. doi: https://doi.org/10.1109/ysf.2017.8126591.

Received 05.04.2021

Accepted 09.05.2021

Published 25.06.2021

Ya.S. Paranchuk ${ }^{1}$, Doctor of Technical Science, Professor, Y.V. Shabatura ${ }^{2}$, Doctor of Technical Science, Professor, O.O. Kuznyetsov ${ }^{2}$, PhD, Associate Professor,

${ }^{1}$ Lviv Polytechnic National University,

12, S. Bandera Str., Lviv, 79013, Ukraine,

e-mail: yparanchuk@yachoo.com

${ }^{2}$ Hetman Petro Sahaidachnyi National Army Academy,

32, Heroes of Maidan Str., Lviv, 79026, Ukraine,

e-mail: shabaturayuriy@gmail.com,

oleksiy.kuznyetsov@ukr.net (Corresponding author)

How to cite this article:

Paranchuk Ya.S., Shabatura Y.V., Kuznyetsov O.O. Electromechanical guidance system based on a fuzzy proportional-plusdifferential position controller. Electrical Engineering \& Electromechanics, 2021, no. 3, pp. 25-31. doi: https://doi.org/10.20998/2074-272X.2021.3.04. 